\title{
Long-term efficacy of crizotinib in a metastatic papillary renal carcinoma with MET amplification: a case report and literature review
}

Philippe Rochigneux ${ }^{1,2^{*}}$, Jeanne Thomassin-Piana ${ }^{3}$, Sophy Laibe ${ }^{4}$, Serge Brunelle ${ }^{5}$, Naji Salem ${ }^{6}$, Bernard Escudier ${ }^{7}$, Gilles Vassal ${ }^{8}$ and Gwenaelle Gravis ${ }^{1}$

\begin{abstract}
Background: Papillary renal cell carcinoma (pRCC) is the 2nd most frequent histological type of kidney cancer and accounts for approximately $15 \%$ of all renal cell carcinoma. It has a poorer prognosis than clear cell RCC (cCRCC) with a lack of standard treatments.

Case presentation: We report the case of a 51 year old man with a metastatic pRCC (hepatic dome and left colonic peritoneal carcinomatosis) progressive after sunitinib, with a MET amplification. The patient was enrolled in the UNICANCER-sponsored AcSé crizotinib trial (NCT02034981), designed to give an access to crizotinib for patients with tumors harboring a genomic alteration on one of the biological targets of the drug. With 2nd line crizotinib (250 mg twice/day), the patient had a very good tolerance, a partial response in the target lesions using RECIST 1.1, and a 19 months' clinical efficacy.
\end{abstract}

Conclusions: In metastatic pRCC with a MET amplification, crizotinib maybe a potential met-inhibitory therapeutic option.

Keywords: Papillary renal cell carcinoma, MET, MET inhibitor, Crizotinib, Radiotherapy

\section{Background}

Papillary renal cell carcinoma (pRCC) is the 2nd most frequent histological type of kidney cancer and accounts for approximately $15 \%$ of all renal cell carcinoma (RCC). The classifications distinguish two types of pRCC: type 1 (more indolent, with basophilic cells) and type 2 (more aggressive, with eosinophilic cells). The prognosis of metastatic pRCC (mpRCC) is worse than in clear cell RCC (ccRCC), with a median PFS around 6 months and a median OS around 12 months, versus 10.5 months and 15.7 months respectively for ccRCC $[1,2]$. For mpRCC, sunitinib or mTor inhibitors are proposed by NCCN Guidelines, but the inclusion in a clinical trial is the preferred option [3]. MET protein is a heterodimer transmembrane

\footnotetext{
* Correspondence: rochigneuxp@ipc.unicancer.fr

'Department of Medical Oncology, Institut Paoli-Calmettes, 232 Bd de Sainte-Marguerite, 13009 Marseille, France

${ }^{2}$ UCLA David Geffen School of Medicine, Los Angeles, USA

Full list of author information is available at the end of the article
}

Tyr-Kinase receptor, with one known ligand (Hepatocyte Growth Factor) and a signaling via MAP-Kinase pathway, leading to increase proliferative functions (invasion, aggressiveness, angiogenesis) [4]. Anomalies of MET pathway have been described in several tumors (NSCLC, gastric, ovaries), and particularly in pRCC where $75 \%$ of hereditary pRCC have activating mutations in the Tyr/Kin domain $[4,5]$. Here we present the case of a patient with a $M E T$-amplified mpRCC successfully treated during 19 months with the MET-inhibitor crizotinib within the French AcSé- crizotinib program [6].

\section{Case presentation}

We describe a patient born in 1961, a manager in the food processing industry, diagnosed with a right renal mass of $50 \mathrm{~mm}$ in February 2012, leading to a partial right nephrectomy. Histopathological examination revealed a tubulo-papillary renal cell carcinoma, type 1,

(c) The Author(s). 2018 Open Access This article is distributed under the terms of the Creative Commons Attribution 4.0 International License (http://creativecommons.org/licenses/by/4.0/), which permits unrestricted use, distribution, and reproduction in any medium, provided you give appropriate credit to the original author(s) and the source, provide a link to the Creative Commons license, and indicate if changes were made. The Creative Commons Public Domain Dedication waiver (http://creativecommons.org/publicdomain/zero/1.0/) applies to the data made available in this article, unless otherwise stated. 
grade 2 of Fuhrman, 20\% of necrosis, without vascular embolus or peri-renal infiltration, R0, pT1bNx, vimentin +, CD 10+. In September 2013, an abdominal computed tomography scan (CT scan) showed a nodular peritoneal infiltration (right peri-colic), with a sub-cutaneous nodule of the right flank, a mild intraperitoneal effusion in the Douglas pouch, and a pre-rectal nodule. After a control CT scan, confirming the stability of the lesions, surgery was performed. The pathological findings (Fig. 1) confirmed the morphology of papillary renal cell carcinoma, with papillary and foamy macrophages (A, B, C) and a positivity of CK7 (D), Racemase/P504S (E) with immunohistochemistry (IHC).

The patient was referred to our Comprehensive Cancer Center in April 2014, with a post-operative abdominal mass. His medical history included cigarette smoking (20 packs/year), thyroidectomy (supplementation), non-insulindependent mellitus diabetes (metformin) and hypertension (amlodipine, valsartan). Clinically, he weighed $78 \mathrm{~kg}$ for $1.80 \mathrm{~m}$, Karnosky performance scale was $80 \%$ and physical examination revealed induration of the abdominal scar. The laboratory tests were normal $(\mathrm{Hb}=14.6 \mathrm{~g} / \mathrm{dl}$, Neutrophil $=2.310^{9} / \mathrm{L}$, Platelets $=326 \mathrm{G} / \mathrm{l}$, absence of hypercalcemia) and the patient was classified in the favorable-risk group according to Heng criteria. Repeat CT scan revealed peritoneal carcinomatosis.

After a multidisciplinary board, a treatment by antiangiogenic sunitinib started in May 2014. Toxicity was mild with grade 1 nausea, grade 2 oesophagitis, and abdominal ascites requiring three ascitic drains. The increase of the peritoneal carcinomatosis was observed on the follow-up CT scan. For this progression, complementary IHC were performed (Fig. 1f), revealing a cMET $100 \%$ (cytoplasmic antibody staining, Roche Diagnostic clone SP44, catalog number 790-4430), a cMET score 3+ (based on number of positive cells and staining intensity), with ROS -, ALK - and no loss of expression of PTEN. This cMET positivity was confirmed by Fluorescence In Situ Hybridization (FISH) of $M E T$ (Fig. 2) realized with a MET/CEN7 Probe (ZytoLight ${ }^{\oplus}$ SPEC MET/CEN7 Dual Color Probe, ZytoVision ${ }^{\oplus}: M E T$ in green, centromere of chromosome 7 in red). The result showed a $M E T$ amplification ( $80 \%$ of positive cells, $M E T>6$ copies per cell, ratio $M E T / C E N 7>2)$. The absence of chromosome 7 and 12 polysomy was verified in a complementary FISH.

After a specific molecular tumor board, the patient was enrolled in the UNICANCER-sponsored AcSé crizotinib trial (NCT02034981) allowing patients with activating genomic alterations in one of crizotinib target genes suffering from a malignancy other than its approved indication to access crizotinib. The patient commenced crizotinib $250 \mathrm{mg}$ twice/day in November 2014. During the treatment, the patient had a very good performance status (ECOG $0-1$ ), with a $100 \%$ professional activity and a stable weight. The only adverse events were grade 1 diarrhoea and asthenia, and no grade 2 or more toxicity was observed. After 3 months of crizotinib, the CT scan demonstrated stable disease, and after 15 months a partial response of $-59 \%$ in the target lesions (hepatic dome: 25 to $10 \mathrm{~mm} /$ left colonic flexure carcinomatosis: 36 to $15 \mathrm{~mm}$ ). The Fig. 3 described the chronological history of the disease (A) and the centralized radiological evolution of the target lesions under crizotinib (RECIST 1.1), that concluded to 5 months partial response (B).

In March 2015, the patient noticed a progression of a left painless inguinal adenopathy of $54 \mathrm{~mm}$, without progression of the other peritoneal lesions and a normal bone scan. In accordance with the protocol, a volumetric-modulated radiotherapy delivered a dose 35 Gy (10 fractions of $3.5 \mathrm{~Gy}$ ) and crizotinib was stopped
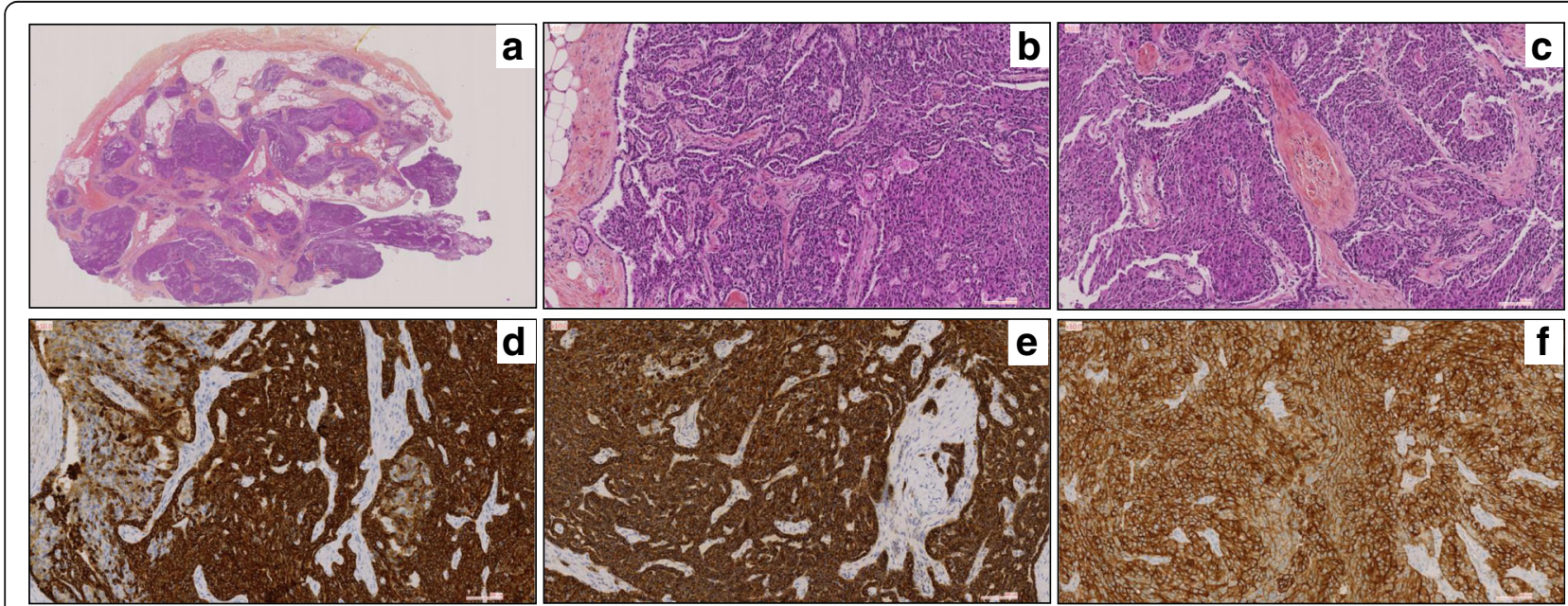

Fig. 1 Microphotographs showing a morphology of papillary renal cell carcinoma, with papillary and foamy macrophages (a) (b) (c). Tumoral cells expressed CK7 (d), Racemase/P504S (e), and C-MET +++ (f) 


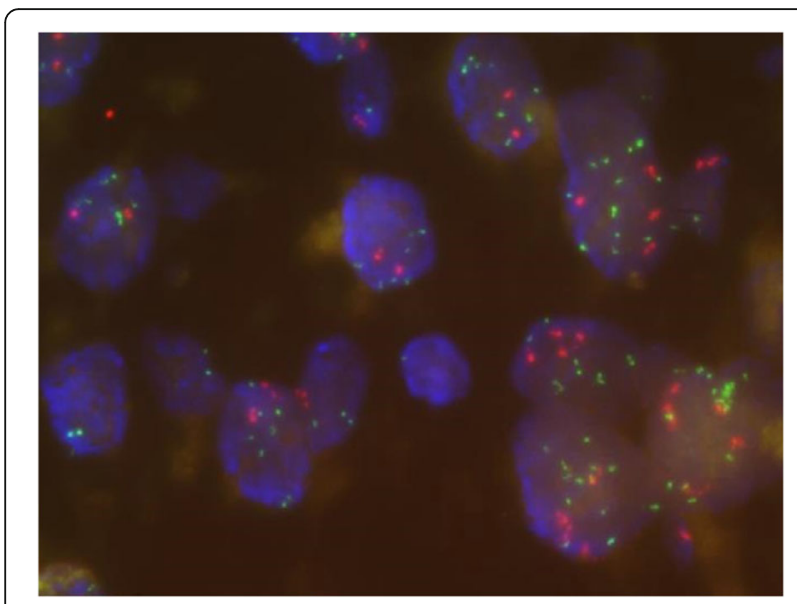

Fig. 2 Fluorescence in situ hybridization (FISH) of MET, realized with a MET/CEN7 Probe (ZytoLight ${ }^{\oplus}$ SPEC MET/CEN7 Dual Color Probe, ZytoVision ${ }^{\circledast}$ ): MET in green, and centromere of chromosome 7 in red). The result showed a MET amplification (MET > 6 copies per cell, and a ratio MET/CEN7 > 2) from the day before to the day after the radiotherapy. In November 2015, the periodic CT scan revealed a new node relapse (left external iliac lymph nodes of 49 $\mathrm{mm})$. A CT-guided biopsy confirmed the diagnosis of papillary renal cell carcinoma, that still expressed C-MET 100\% (score 3+). Therefore, due to the success of the first treatment, a 2nd radiotherapy was performed (42.5 Gy).

Crizotinib was continued for another 6 months, with a good tolerance (ECOG 0 with $100 \%$ professional activity) and clinical efficacy. As presented in the comparative CT scans of Fig. 4, after 17 months of crizotinib, the patient was still in ongoing response in the peritoneal carcinomatosis lesions (hepatic dome in red arrow, omental cake in white arrow) and in ascites (red and white star).

On May 2016, after 19 months of crizotinib, a relapse was observed with ascites and the patient was treated with axitinib. Three months later, the patient died of progression.

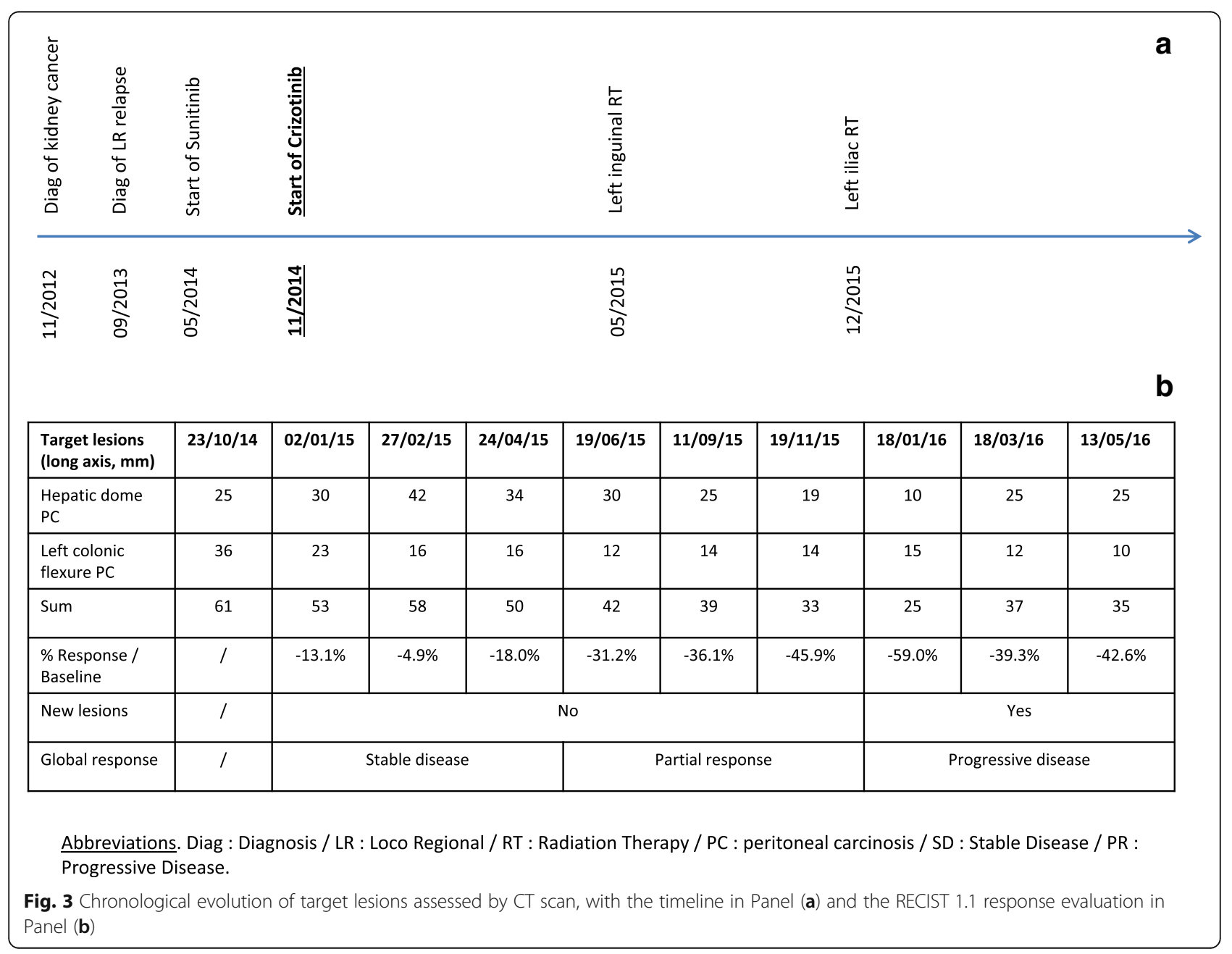



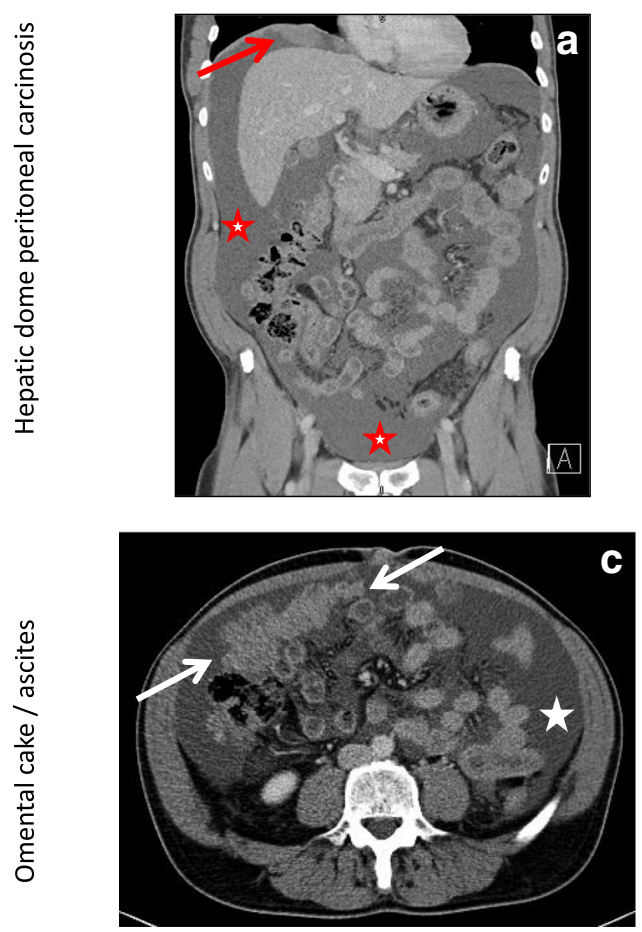

$23 / 10 / 2014$

Before Crizotinib
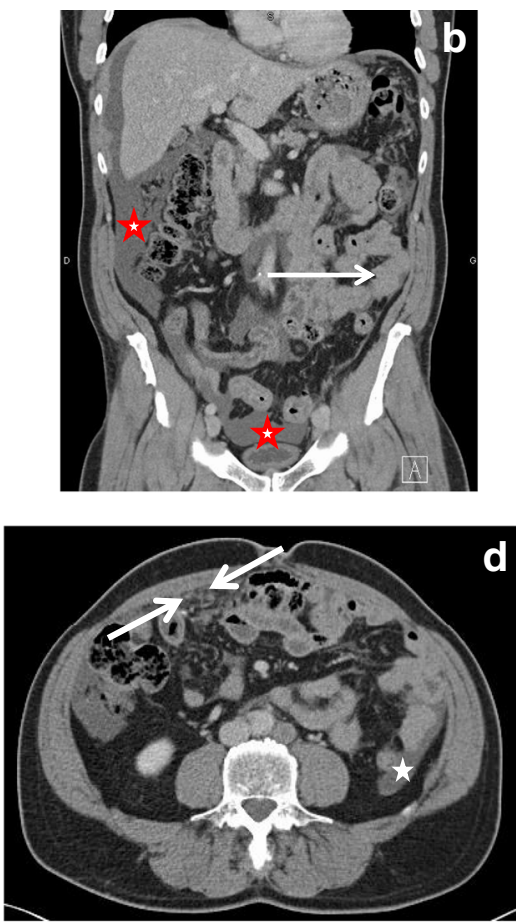

$18 / 03 / 2016$

After 17 months of Crizotinib

Fig. 4 Radiological comparison of abdominopelvic CT scans before crizotininb $(\mathbf{a}, \mathbf{c})$ and after 17 months of crizotinib (b, d), in coronal (a, b) and transversal plane $(\mathbf{c}, \mathbf{d})$

\section{Discussion and conclusion}

MpRCC can be an aggressive disease with a lack of standard treatments, as the most classical drug in 1st line (sunitinib) was only studied in small phase II studies. In 2015, Ravaud et al. treated 61 patients with sunitinib (15 type 1 mpRCC / 46 type 2) with a modest median PFS of 6.6 months (type 1) and 5.5 months (type 2) and only $7 / 61$ partial response [2]. Moreover, mTOR inhibitor everolimus has been shown to be less efficient than sunitinib in non-ccRCC $[7,8]$. Data concerning pazopanib are scarce [9].

Here, we present the case of a man with a mpRCC, progressive after sunitinib, for which the diagnosis of $M E T$ amplification led to use crizotinib in 2nd line with a 19 months' efficacy, and a very good tolerance (ECOG $0,100 \%$ professional activity). The multidisciplinary collaboration of pathologist, molecular biologist, radiation oncologist and medical oncologist led to this successful example of personalized medicine via MET targeting. Interestingly, Diamond et al. described a pRCC patient with an activating $M E T$ gene mutation, pretreated by sunitinib and everolimus, with a long response to a tyrosine kinase inhibitor (TKI: PF-04217903) [10]. But this situation is rare in routine clinical practice, as MET copy number amplifications are more frequent in pRCC $(81 \%$ of type 1 in the series of Albiges et al.) than intracellular domain $M E T$ mutations (21\%) [11]; moreover the development of this TKI has stopped.

Biologically, the proof of $M E T$ implication in pRCC was made in 1997 with the discovery that hereditary pRCC patients had a germline missense mutation in the $M E T$ proto-oncogene (7q3 locus), leading to constitutive activation of the MET protein [12]. Recently, a translational analysis of 220 pRCC revealed the presence of DNA copy number alterations (gain) in $46 \%$ of type 2 pRCC and in $81 \%$ of type 1 pRCC, significantly higher than in clear cell RCC [11]. And it has been published earlier that gene copy number increase is associated with upregulation of MET protein expression [13]. Another large series of pRCC $(n=164)$ described MET mutations in 17 tumors, mainly in type $1 \mathrm{pRCC}$ and in the tyrosine kinase domain (14/17), and discovered an alternate MET RNA transcript leading to a constitutive activation of MET in a ligand-independent manner [14].

This biological evidence for the implication of MET in both hereditary and sporadic pRCC have led to design trials with MET inhibitors in pRCC $[15,16]$. However, the preliminary results of MET targeting were disappointing. First, foretinib (MET/VEGFR2 inhibitor) was examined in a phase II including 74 patients with mpRCC: the median PFS was 9.3 months and patients with a germline mutation were significantly more likely to respond [17]. No 
responses were observed in patients with $M E T$-amplification $(n=2)$ and only $1 / 18$ patients $(5 \%)$ with a gain of chromosome 7 responded. Second, tivantinib (selective oral MET inhibitor) had very poor outcomes in PFS (median: 2 months) and OS (median 10 months) and had a $0 \%$ response rate $(n=70)$ [18]. Thirdly, savolitinib (AZD6094 or volitinib, selective MET inhibitor) was recently tested in a single-arm, multicenter, phase II study $(n=109)$ [19]. Interestingly, if the response rate was $0 \%$ in METindependent $\mathrm{pRCC}$, it was of $18 \%$ in patients with a METdriven pRCC (chromosome 7 copy gain, focal MET or HGF gene amplification, or MET kinase domain mutations). To broaden this strategy of MET targeting, the SWOG 1500 (PAPMET trial, phase II) was designed as a multi-arm trial of three MET inhibitors (cabozantinib, volitinib or crizotinib) versus sunitinib [20]. This trial will include 180 patients and the first results (primary outcome: PFS) are expected for 2020. Interestingly, several biomarkers are included in the trial, either integrated (MET mutation / MET expression) or exploratory (genomic profiling), which will add precious biological knowledge.

Concerning crizotinib, this treatment is a currently available MET-ALK-ROS1 inhibitor, with a favourable toxicity profile, and is well known by medical oncologists for the treatment of non-small cell lung cancer [21, 22]. At the time we treated this patient, no data was available concerning the efficacy of crizotinib in pRCC. Only a previous case report described a MET-mutated pRCC patient pre-treated with sunitinib and tivantinib [23]; however this mutation (missense base substitution MET H1094L) is rare compared to MET amplification, and the patient only remained on crizotinib therapy for 5 months (versus 19 months in our patient). Our report also highlights the feasibility and efficacy of a focal irradiation in the situation of a pRCC patients treated with crizotininb (with suspension of crizotinib from the day before to the day after radiotherapy). Interestingly, in November 2017 were published the results of pRCC1 patients included in the CREATE trial (EORTC 90101), a multicentric prospective phase II clinical trial including patients with tumors harboring specific alterations leading to ALK and/or MET activation and treated with crizotinib [24]. Among the 4 MET-driven pRCC1 patients, the ORR was $50 \%$, with a 1 -year PFS rate $=75 \%$, whereas among the 16 MET-independent pRCC1 patients, the ORR was $6.3 \%$ with a 1 -year PFS rate $=27 \%$. This study demonstrated that crizotinib is active in pRCC, achieving long-lasting disease control in patients with MET mutations or amplification.

Our case report illustrates and reinforces this finding that crizotinib is more active in MET driven pRCC, and that a precise molecular diagnosis is crucial for the optimal care of pRCC. This precision treatment (crizotinib) was possible thanks to an original biology-driven national
French program (AcSé crizotinib NCT02034981), giving access to crizotinib for patients with identified activating genomic alterations in the crizotinib target genes, with a safe monitoring [25]. Today, this academic national program (28 regional centers), enrolled more than 235 patients with refractory malignancies and no therapeutic alternative [26]. In ASCO 2018, the results of AcSé crizotinib trials demonstrated the efficacy of crizotinib in chemo-refractory MET-amplified esogastric adenocarcinomas $(\mathrm{ORR}=42.8 \%)$ [27]. The data are not yet mature for a specific analysis of pRCC patients, but this case report and the data of CREATE study are promising results of precision medicine in $\mathrm{PRCC}$.

In conclusion, the molecular documentation of MET in pRCC seems crucial, as MET inhibitors like crizotinib are effective, safe, and nowadays available.

\section{Abbreviations \\ AcSé program: For "secure access to innovative targeted therapies"; cCRCC: Clear cell renal cell carcinoma; CEN: Centromere; ECOG: Eastern Cooperative Oncology Group; MET: Mesenchymal epithelial transition proto- oncogene; mpRCC: Metastatic papillary renal cell carcinoma; NSCLC: Non small cell lung cancer; pRCC: Papillary renal cell carcinoma; RCC: Renal cell carcinoma; RECIST: Response evaluation criteria in solid tumors; TKI: Tyrosine kinase inhibitor}

\section{Acknowledgments}

We thank Emilie Agavnian-Couquiau for her help in the pathological scanning. We thank Brice Chanez for his help in the revision of the manuscript.

\section{Funding}

The French National Cancer Institute and Foundation ARC against cancer supported the Acsé Program (design of the study, data collection and data analysis). The Paoli Calmettes Institute supported the clinical facilities for patient's diagnosis and treatment. No funding source were involved in the interpretation of data and the writing of the manuscript.

\section{Availability of data and materials}

The datasets used during the current study are in Institut Paoli Calmettes and are available from the corresponding author on reasonable request.

\section{Authors' contributions}

PR and GG designed the research and wrote the paper. JTP performed the histological examination and SL performed the FISH analysis. PR, JTP, $\mathrm{SL}, \mathrm{SB}, \mathrm{NS}, \mathrm{BE}, \mathrm{GV}$ and GG collaborated on the paper's conception, reviewed the paper and approved the final version of the article to be published.

\section{Ethics approval and consent to participate}

The AcSé trial (NCT02034981) was approved by French ethics committee (name: CPP IDF VII - Hopitâl de Bicêre / reference number: 20013000-885-13).

Consent for publication

Written informed consent was obtained from the patient for publication of this case report and any accompanying images.

Competing interests

The authors declare that they have no competing interests.

\section{Publisher's Note}

Springer Nature remains neutral with regard to jurisdictional claims in published maps and institutional affiliations. 


\section{Author details}

'Department of Medical Oncology, Institut Paoli-Calmettes, 232 Bd de Sainte-Marguerite, 13009 Marseille, France. ${ }^{2}$ UCLA David Geffen School of Medicine, Los Angeles, USA. ${ }^{3}$ Department of Pathology, Institut Paoli-Calmettes, Marseille, France. ${ }^{4}$ Department of Cytogenetics and Molecular Genetics, Institut Paoli-Calmettes, Marseille, France. ${ }^{5}$ Department of Radiology, Institut Paoli-Calmettes, Marseille, France. ${ }^{6}$ Department of Radiotherapy, Institut Paoli-Calmettes, Marseille, France. ${ }^{7}$ Department of Medical Oncology, Gustave Roussy Cancer Center, Villejuif, France. ${ }^{8}$ Direction of Clinical Research, Gustave Roussy Cancer Center, Villejuif, France.

Received: 22 November 2017 Accepted: 6 November 2018 Published online: 22 November 2018

\section{References}

1. Choueiri TK, Plantade A, Elson P, et al. Efficacy of sunitinib and sorafenib in metastatic papillary and chromophobe renal cell carcinoma. J Clin Oncol. 2008:26:127-31.

2. Ravaud A, Oudard S, De Fromont M, et al. First-line treatment with sunitinib for type 1 and type 2 locally advanced or metastatic papillary renal cell carcinoma: a phase II study (SUPAP) by the French Genitourinary Group (GETUG). Ann Oncol. 2015;26:1123-8.

3. NCCN. NCCN clinical practice guidelines in oncology-kidney cancer. Available from: https:/www.nccn.org/professionals/physician_gls/f_ guidelines.asp\#site. [cited 30 Jan 2017].

4. Appleman LJ. MET signaling pathway: a rational target for cancer therapy. J Clin Oncol. 2011;29:4837-8.

5. Petrini I. Biology of MET: a double life between normal tissue repair and tumor progression. Ann Transl Med. 2015;3:82.

6. Buzyn A, Blay J-Y, Hoog-Labouret N, et al. Equal access to innovative therapies and precision cancer care. Nat Rev Clin Oncol. 2016;13:385-93.

7. Armstrong AJ, Halabi S, Eisen T, et al. Everolimus versus sunitinib for patients with metastatic non-clear cell renal cell carcinoma (ASPEN): a multicentre, open-label, randomised phase 2 trial. Lancet Oncol. 2016;17: 378-88

8. Tannir NM, Jonasch E, Albiges L, et al. Everolimus versus sunitinib prospective evaluation in metastatic non-clear cell renal cell carcinoma (ESPN): a randomized multicenter phase 2 trial. Eur Urol. 2016;69:866-74.

9. Matrana MR, Baiomy A, Campbell M, Alamri S, Shetty A, Teegavarapu P, Kalra S, et al. Outcomes of patients with metastatic non-clear-cell renal cell carcinoma treated with pazopanib. Clin Genitourin Cancer. 2017;15(2).

10. Diamond JR, Salgia R, Varella-Garcia M, et al. Initial clinical sensitivity and acquired resistance to MET inhibition in MET-mutated papillary renal cell carcinoma. J Clin Oncol. 2013;31:e254-8.

11. Albiges $L$, Guegan J, Formal AL, et al. MET is a potential target across all papillary renal cell carcinomas: result from a large molecular study of pRCC with CGH array and matching gene expression array. Clin Cancer Res. 2014; 20:3411-21.

12. Schmidt L, Duh FM, Chen F, et al. Germline and somatic mutations in the tyrosine kinase domain of the MET proto-oncogene in papillary renal carcinomas. Nat Genet. 1997;16:68-73.

13. Glukhova L, Lavialle C, Fauvet D, et al. Mapping of the $7 q 31$ subregion common to the small chromosome 7 derivatives from two sporadic papillary renal cell carcinomas: increased copy number and overexpression of the MET proto-oncogene. Oncogene. 2000;19:754-61.

14. The Cancer Genome Atlas Research. Comprehensive molecular characterization of papillary renal-cell carcinoma. N Engl J Med. 2016;374:135-45.

15. Ciccarese C, Massari F, Santoni M, et al. New molecular targets in non clear renal cell carcinoma: an overview of ongoing clinical trials. Cancer Treat Rev. 2015:41:614-22.

16. Garajová I, Giovannetti E, Biasco G, et al. c-Met as a target for personalized therapy. Transl Oncogenomics. 2015;7:13-31.

17. Choueiri TK, Vaishampayan U, Rosenberg JE, et al. Phase II and biomarker study of the dual METNEGFR2 inhibitor foretinib in patients with papillary renal cell carcinoma. J Clin Oncol. 2013;31:181-6.

18. Twardowski P, Plets M. SWOG 1107: parallel (randomized) phase ॥ evaluation of tivantinib (ARQ-197) and tivantinib in combination with erlotinib in patients (Pts) with papillary renal cell carcinoma (pRCC). J Clin Oncol:33(15 suppl). Available from: http://ascopubs.org/doi/abs/10.1200/jco. 2015.33.15_suppl.4523. [cited 11 Oct 2018].
19. Choueiri TK, Plimack E, Arkenau H-T, et al. Biomarker-based phase II trial of savolitinib in patients with advanced papillary renal cell cancer. J Clin Oncol. 2017;35:2993-3001.

20. Cabozantinib s-malate, crizotinib, volitinib, or sunitinib malate in treating patients with locally advanced or metastatic kidney cancer - Full Text View ClinicalTrials.gov. Available from: https://clinicaltrials.gov/ct2/show/ NCT02761057. [cited 11 Oct 2018].

21. Shaw AT, S-HI O, Bang Y-J, et al. Crizotinib in ROS1-rearranged non-smallcell lung cancer. N Engl J Med. 2014;371:1963-71.

22. Shaw AT, Kim D-W, Nakagawa K, Seto T, Crinó L, Ahn M-J, De Pas T, et al. Crizotinib versus chemotherapy in advanced ALK-positive lung cancer N Engl J Med. 2013;368:2385-94.

23. Stein MN, Hirshfield KM, Zhong H, et al. Response to crizotinib in a patient with MET-mutant papillary renal cell cancer after progression on tivantinib. Eur Urol. 2015:67:353-4.

24. Schöffski P, Wozniak A, Escudier B, et al. Crizotinib achieves long-lasting disease control in advanced papillary renal-cell carcinoma type 1 patients with MET mutations or amplification. EORTC 90101 CREATE trial. Eur J Cancer. 2017;87:147-63.

25. ClinicalTrials: phase 2 study assessing efficacy and safety of crizotinib in patients harboring an alteration on ALK, MET or ROS1 - Tabular View ClinicalTrials.gov. Available from: https://clinicaltrials.gov/ct2/show/record/ NCT02034981. [cited 10 Feb 2017].

26. Vassal G. Meeting Library | Biomarker-driven access to crizotinib in ALK, MET, or ROS1 positive (+) malignancies in adults and children: The French National AcSé Program. Available from: https://meetinglibrary.asco.org/ record/158633/abstract. [cited 12 Oct 2018].

27. Aparicio T. Meeting Library / The activity of crizotinib in chemo-refractory MET-amplified esogastric adenocarcinomas: results from the AcSé-crizotinib program. Available from: https://meetinglibrary.asco.org/record/160162/ abstract. [cited 12 Oct 2018].

\section{Ready to submit your research? Choose BMC and benefit from:}

- fast, convenient online submission

- thorough peer review by experienced researchers in your field

- rapid publication on acceptance

- support for research data, including large and complex data types

- gold Open Access which fosters wider collaboration and increased citations

- maximum visibility for your research: over $100 \mathrm{M}$ website views per year

At $\mathrm{BMC}$, research is always in progress.

Learn more biomedcentral.com/submissions 